\title{
Adherence to post-surgery follow-up assessment and its association with sociodemographic and disease characteristics in patients with breast cancer in Central China
}

\author{
Ran Feng ${ }^{1}$, Jingfeng Jing ${ }^{1}$, Xiaojun Zhang ${ }^{1}$, Ming $\mathrm{Li}^{2}$ and Jinnan Gao ${ }^{1 *}$ (i)
}

\begin{abstract}
Background: Follow-up after curative surgery is increasingly recognized as an important component of breast cancer care. Although current guideline regulates the follow-ups, there are no relevant studies on the adherence to it in China. This study investigated the post-surgery follow-up and explored its association with patients, tumor and treatment characteristics.

Methods: A total of 711 patients underwent surgical treatment in Shanxi Bethune Hospital from March 2012 to May 2018 were included in this study. Baseline sociodemographic, tumor, and treatment characteristics were obtained from the hospital electronic medical records. The post-surgery follow-up was reviewed and assessed from the patient's follow-up examination record. Factors associated with the first three-year follow up was evaluated using logistic regression analysis.

Results: The annual follow-up rate after surgery decreased gradually from $67.1 \%$ at the 1 st year, $60.2 \%$ at the $3 r d$ year to $51.9 \%$ at the 4 th year, and $43.5 \%$ at the 5 th year. Loss of follow-up during the first 3 years after surgery was significantly associated with older age (> 65 years), lower medical insurance coverage, axillary lymph node dissection, and less intensity of systemic treatment.

Conclusion: A significant downtrend of annual follow-up rate for breast cancer survivors was confirmed in this study. Loss of follow-up within the first 3 years after surgery was associated with both patient's characteristics and treatment. These results will provide evidence to help clinicians to develop tailored patient management after curative surgery.
\end{abstract}

Keywords: Follow-up, Adherence, Breast cancer, China

\footnotetext{
*Correspondence: 15135086600@163.com; Gaojinnan@sxmu.edu.cn

${ }^{1}$ Department of Breast Surgery, The Affiliated Shanxi Bethune Hospital of

Shanxi Medical University, 99 Longcheng Street, Taiyuan 030032, Xiaodian

District, China

Full list of author information is available at the end of the article
}

(c) The Author(s). 2020 Open Access This article is licensed under a Creative Commons Attribution 4.0 International License, which permits use, sharing, adaptation, distribution and reproduction in any medium or format, as long as you give appropriate credit to the original author(s) and the source, provide a link to the Creative Commons licence, and indicate if changes were made. The images or other third party material in this article are included in the article's Creative Commons licence, unless indicated otherwise in a credit line to the material. If material is not included in the article's Creative Commons licence and your intended use is not permitted by statutory regulation or exceeds the permitted use, you will need to obtain permission directly from the copyright holder. To view a copy of this licence, visit http://creativecommons.org/licenses/by/4.0/ The Creative Commons Public Domain Dedication waiver (http://creativecommons.org/publicdomain/zero/1.0/) applies to the data made available in this article, unless otherwise stated in a credit line to the data. 


\section{Background}

The incidence of breast cancer has increased more than $30 \%$ in the past decades in China [1]. Epidemiological studies based on international and Chinese data have showed that breast cancer is the most common one in female malignant tumors [2, 3]. Breast cancer patients with early breast cancer have better survival, lower recurrence and metastasis rate due to early diagnosis and improved treatment [4].

As an important element in the comprehensive management of breast cancer patients [5], follow-up (hereinafter as FU) can eliminate treatment-related complications, detect recurrence and metastasis as early as possible, and improve mental health and quality of life. The National Comprehensive Cancer Network (NCCN) clinical practice guidelines suggest monitoring breast cancer patients closely and recommending mammography every 12 month [5]. Chinese guidelines recommend that a FU every 3 months in the first 2 years after the operation (or after adjuvant chemotherapy is finished), every 4 to 6 months for the 3rd to 4th year, and 1 to 2 times annually after the 5 th year [6]. In our clinical practice, we follow the guidelines for all patients of varied risk with stage 0-III. Our patients had been reminded for FU check via phone or other means (eg. WeChat) as much as possible by nurses. But FU examination and care can only be conducted among patients with good compliance and fail among patients with poor adherence who may require extra attention for post-surgery care due to lack of evidence.

Loss of FU often leads to treatment interruption or treatment plan change which increases the risk of rehospitalization. Besides, as for the breast cancer patients, the annualized hazard of recurrence was the highest during the first 5 years peaking during the first 3 years [7], at which time FU is essential for patient's long-term prognosis. The post-operation management of breast cancer patients in China includes FU treatment such as endocrine therapy and management of treatment side effects [6]. But at times in our practice, patients' postoperation care needs, for example, professional guidance in rehabilitation, mental wellbeing, and alternative medicine or Chinese medicine, or lifestyle consultation could not be met. The gap in comprehensive care is calling for continuous multidisciplinary care service for optimal patient management which has been reported beneficial to prognosis [8]. In addition, systemic FU management at the government level in China has not been established as in European and American countries [9, 10]. Therefore, the major challenge in clinical practice in China is that clinicians have no evidence-based protocol regarding follow up meeting patients' needs and for subgroup patients, for example, for patients with poor accessibility to health facilitates or with comorbidities, or with financial stress. In facing with the increasing individualized
FU [11], evidence is urgently required to better define the patient's care needs and develop appropriate FU program for subgroups to improve the adherence [12]. Currently, FU adherence after breast surgery has not been studied in China.

Therefore, the purpose of this study was to describe the adherence to post-surgery FU guideline and its association with patient's, tumor and treatment characteristics in a cohort of breast cancer patients having curative surgery in a tertiary hospital in central China.

\section{Methods}

\section{Data source and study population}

Patient registry database in the Breast Surgery Department at Shanxi Bethune Hospital, Shanxi, China, was established in 2012 and collects the information about disease and treatment of all patients with breast cancer admitted in the hospital. Sociodemographic information includes age, medical insurance coverage, marital status, family history. Disease profile includes tumor size, axillary node status, TNM stage, histological subtype, estrogen and progesterone receptor (ER, PR) status, human epidermal growth factor receptor 2 (HER2) status. Detailed information about breast and/or node surgery, chemotherapy, radiotherapy, endocrine therapy, targeted therapy was also included. The study was approved by the Ethics Committee of Shanxi Bethune Hospital (No: YXLL-2019-130).

The database recorded 801 female patients, who were diagnosed with breast cancer and underwent surgical treatment from March 2012 to May 2018. A total of 711 patients were included in the study after excluding 19 patients with stage IV disease, 49 patients with another malignancy, and 22 patients who died before May 2019 (Supplement Figure).

FU was assessed by reviewing records of post-operation imaging examinations including mammography and breast ultrasound $[5,6]$ at the imaging center of Shanxi Bethune Hospital from April to May 2019. Adherence to FU was defined as having at least one record in the consecutive following year after the surgery, otherwise as loss of $\mathrm{FU}$ in the corresponding year.

\section{Statistical analysis}

Annual FU rate was calculated by dividing the number of patients having follow-up examination(s) by the number of eligible patients at the corresponding year (Supplement Table 1) and was compared with Chi-square test.

Considering the recurrence rate peaking in the first 3 years after surgery, patients having had surgery before May $2016(n=420)$ were included for subsequent analysis after excluding 291 patients having surgery in 2017 and 2018 (Supplement Figure). FU frequency during the first 3 years after curative surgery was compared by patients, 
disease, and treatment characteristics using Chi-square test. Factors associated with complete loss FU for all 3 years (loss at years 1,2, and 3) were investigated with step-wise logistic regressions. In addition, factors associated with loss of $\mathrm{FU}$ at year 3 following curative surgery were identified using stepwise generalized linear regression analysis with family being "binomial" and link function being "log" to avoid biased association since the loss of follow up rate was as high as $39.8 \%$ at the 3rd year [13]. The adjusted results were the final full model from the regression analyses. The following factors were evaluated: age, medical insurance coverage, family history, marital status, employment, tumor size, axillary nodes status, TNM stage, histological types, ER status, PR, HER2 status, and treatment received. Variables with $P<$ 0.10 in univariate analysis were initially included in the multivariate analysis and eliminated each at one time in step-wise regression model justified by likelihood ratio test [13]. The candidate factors included: age, insurance coverage, marital status, tumor size, axillary node surgery, and treatment. Analysis was carried out using SPSS. A two-tailed $p$ values $<0.05$ were considered as statistically significant.

\section{Results}

\section{Annual follow-up}

The median FU of these patients was 29 months, ranging from 5 to 84 months. The annual FU rates at the first and second year after surgery were 67.1 and $70.6 \%$. There was no significant difference in FU rate between them $(p=0.183)$. However, it dropped to $60.2 \%(p=$ 0.020 )at the third year, and continuously dropped to $51.9 \%(p<0.001)$ at the 4 th and $43.5 \%(p<0.001)$ at the 5 th year (Table 1$)$.

Follow-up adherence during the first $\mathbf{3}$ years after surgery A total of 420 patients was included to assess the FU within 3 years after surgery. The median age at diagnosis was 52 years old (ranging 23-83 years). Among them, five patients (1.2\%) had stage 0 cancer, $149(35.5 \%)$ were diagnosed stage I, 202 (48.1\%) stage II, 64 (15.2\%) stage III. $94(22.4 \%)$ patients had no FU in the first 3 years; while 197 (46.9\%) patients had FU imaging each year. Only $7(1.7 \%)$ patients went for FU in the first 2 years but not at the 3rd year.
Loss of FU were more likely in patients who were: older, or having lower insurance coverage, or more extensive axillary node surgery, or no treatments. However, it did not differ by family history, marital or employment status, cancer staging or receptor tests, or breast surgery type (Table 2).

Table 3 showed factors associated with complete loss of FU for all 3 years (loss at years 1, 2, and 3) after surgery. Candidate factors eliminated subsequently were tumor size, targeted therapy, marital status, and endocrine therapy. The odds ratio (OR) of loss FU was 2.31 [95\% confidence interval (CI) 1.13-4.73] for those aged over 65 years. Patients having lower medical insurance coverage of $50-75 \%$ and $<50 \%$ were 3.21 (95\% CI $1.53-$ $6.73)$ and 3.58 (95\% CI 1.57-8.15) times the odds to loss FU examinations compared to those with high coverage of over $70 \%$. The odds of loss of FU was 2.51 (95\% CI 1.39-4.52) times in those with axillary lymph node dissection. Poor FU adherence was more likely in patients without chemotherapy (OR 3.48, 95\% CI 1.84-6.57), and radiotherapy (OR 3.90, 95\% CI 2.14-7.10). The above significant associated factors with loss of $\mathrm{FU}$ at year 3 after surgery were confirmed the same (Supplement Table 2).

\section{Discussion}

This study showed that FU rates after surgery decreased within the five-year period from $67.1 \%$ in the first year to $60.2 \%$ at the third year, down to $43.5 \%$ at the fifth year. This decreasing trend has been consistently reported in other populations [14-16]. For example, a Dutch study of patients with breast cancer found that the first year of FU was $82 \%$ and it dropped to $68.5 \%$ at the fourth year [14]. A Canadian longitudinal study found that about $80 \%$ of patients had at least one $\mathrm{FU}$ at the first 4 years, and it dropped to $73 \%$ at the fifth year [15]. An American study on outpatient FU rate showed a decrease from $50 \%$ at the first year to $27 \%$ at the third year [16]. Although the annual FU rates from the existing studies vary substantially, the annual down trend is unquestionable. The FU rates in this study was generally lower than that of European and American countries. One reason is that in China, especially in the central region, primary care or a systematic tracking data platform

Table 1 The annual follow-up rate in cancer patients undergone curative surgery during 2012-2018 (N=711)

\begin{tabular}{llllll}
\hline Annual follow-up & Total patients & Follow-up & Lost follow-up & $\mathbf{X}^{\mathbf{2}}$ & $\boldsymbol{p}^{*}$ \\
\hline 1st year & 711 & $477(67.1 \%)$ & $234(32.9 \%)$ & $162(29.4 \%)$ & 1.78 \\
2nd year & 551 & $389(70.6 \%)$ & $167(39.8 \%)$ & 5.42 & 0.02 \\
3rd year & 420 & $253(60.2 \%)$ & $137(48.1 \%)$ & 20.00 & $<0.01$ \\
4th year & 285 & $148(51.9 \%)$ & $100(56.5 \%)$ & 33.60 & $<0.01$ \\
5th year & 177 & $77(43.5 \%)$ & &
\end{tabular}

*Annual follow-up rate after surgery were compared with the first year using a Chi-square test 
Table 2 Post-operation follow-up during the first 3 years by sociodemographic and clinical profile $(N=420)$

\begin{tabular}{|c|c|c|c|c|c|c|}
\hline \multirow[t]{2}{*}{ Characteristic } & \multicolumn{4}{|c|}{ Frequency of follow-up in the first 3 years } & \multirow{2}{*}{$\begin{array}{l}\text { Total } \\
N=420\end{array}$} & \multirow[t]{2}{*}{$p^{*}$} \\
\hline & $0 n=94$ & $1 n=50$ & $2 n=79$ & $3 n=197$ & & \\
\hline Age(years) & & & & & & $<0.01$ \\
\hline$\leq 65$ & $58(61.7 \%)$ & $39(78.0 \%)$ & $66(83.5 \%)$ & $189(95.9 \%)$ & $352(83.8 \%)$ & \\
\hline$>65$ & $36(38.3 \%)$ & $11(22.0 \%)$ & $13(16.5 \%)$ & $8(4.1 \%)$ & $68(16.2 \%)$ & \\
\hline Medical insurance coverage & & & & & & $<0.01$ \\
\hline High $(\geq 70 \%)$ & $16(17.0 \%)$ & $10(20.0 \%)$ & $24(30.4 \%)$ & 77 (39.1\%) & $127(30.2 \%)$ & \\
\hline Medium (50-70\%) & $50(53.2 \%)$ & $29(58.0 \%)$ & $35(44.3 \%)$ & $83(42.1 \%)$ & $197(46.9 \%)$ & \\
\hline Low $(\leq 50 \%)$ & $28(29.8 \%)$ & $11(22.0 \%)$ & $20(25.3 \%)$ & $37(18.8 \%)$ & $96(22.9 \%)$ & \\
\hline Family history & & & & & & 0.89 \\
\hline Negative & $88(93.5 \%)$ & 47 (94.0\%) & $76(96.2 \%)$ & $186(94.4 \%)$ & $397(94.5 \%)$ & \\
\hline Positive & $6(6.4 \%)$ & $3(6.0 \%)$ & $3(3.8 \%)$ & $11(5.6 \%)$ & $23(5.5 \%)$ & \\
\hline Marital status & & & & & & 0.31 \\
\hline Unmarried & $9(9.6 \%)$ & $2(4.0 \%)$ & $3(3.8 \%)$ & $10(5.1 \%)$ & $24(5.7 \%)$ & \\
\hline Married & 85 (90.4\%) & $48(96.0 \%)$ & $76(96.2 \%)$ & $187(94.9 \%)$ & $396(94.3 \%)$ & \\
\hline Employment & & & & & & 0.84 \\
\hline Employed & $65(69.1 \%)$ & 37 (74.0\%) & $51(64.6 \%)$ & $130(66.0 \%)$ & $283(67.4 \%)$ & \\
\hline Unemployed & $13(13.8 \%)$ & $4(8.0 \%)$ & $9(11.4 \%)$ & $25(12.7 \%)$ & $51(12.1 \%)$ & \\
\hline Retired & $16(17.0 \%)$ & $9(18.0 \%)$ & $19(24.1 \%)$ & $42(21.3 \%)$ & $86(20.5 \%)$ & \\
\hline Tumor size $(\mathrm{cm})$ & & & & & & 0.40 \\
\hline $0-1.9$ & $33(35.1 \%)$ & $18(36.0 \%)$ & $33(41.8 \%)$ & $87(44.2 \%)$ & $171(40.7 \%)$ & \\
\hline $2-4.9$ & $54(57.4 \%)$ & $30(60.0 \%)$ & $41(51.9 \%)$ & $105(53.3 \%)$ & $230(54.8 \%)$ & \\
\hline$\geq 5$ & $7(7.4 \%)$ & $2(4.0 \%)$ & $5(6.3 \%)$ & $5(2.5 \%)$ & $19(4.5 \%)$ & \\
\hline Positive axillary nodal status & & & & & & 0.80 \\
\hline 0 & 47 (50.0\%) & $26(52.0 \%)$ & $46(58.2 \%)$ & $112(56.9 \%)$ & $231(55.0 \%)$ & \\
\hline $1-3$ & $29(30.9 \%)$ & $18(36.0 \%)$ & $20(25.3 \%)$ & $61(31.0 \%)$ & $128(30.5 \%)$ & \\
\hline $4-9$ & $12(12.8 \%)$ & $4(8.0 \%)$ & $7(8.9 \%)$ & $16(8.1 \%)$ & $39(9.3 \%)$ & \\
\hline$\geq 10$ & $6(6.4 \%)$ & $2(4.0 \%)$ & $6(7.6 \%)$ & $8(4.1 \%)$ & $22(5.2 \%)$ & \\
\hline TNM stage & & & & & & 0.86 \\
\hline Stage $0-I$ & $31(33.0 \%)$ & 19 (38.0\%) & $30(38.0 \%)$ & $74(37.6 \%)$ & $154(36.7 \%)$ & \\
\hline Stage II & $46(48.9 \%)$ & $23(46.0 \%)$ & $35(44.3 \%)$ & 98 (49.7\%) & $202(48.1 \%)$ & \\
\hline Stage III & $17(18.1 \%)$ & $8(16.0 \%)$ & $14(17.7 \%)$ & $25(12.7 \%)$ & $64(15.2 \%)$ & \\
\hline Histological subtype & & & & & & 0.65 \\
\hline Tubular/Mucinous/Papillary & $1(1.1 \%)$ & $3(6.0 \%)$ & $2(2.5 \%)$ & $8(4.1 \%)$ & $14(3.3 \%)$ & \\
\hline Ductal/Lobular/Mixed/Metaplastic & $90(95.7 \%)$ & $46(92.0 \%)$ & $76(96.2 \%)$ & $186(94.4 \%)$ & $398(94.8 \%)$ & \\
\hline Ductal carcinoma in situ & $3(3.2 \%)$ & $1(2.0 \%)$ & $1(1.3 \%)$ & $3(1.5 \%)$ & $8(1.9 \%)$ & \\
\hline ER status & & & & & & 0.16 \\
\hline Negative & $25(26.6 \%)$ & 21 (42.0\%) & 19 (24.1\%) & 64 (32.5\%) & 129 (30.7\%) & \\
\hline Positive & 69 (73.4\%) & 29 (58.0\%) & 57 (72.2\%) & $132(67.0 \%)$ & $287(68.3 \%)$ & \\
\hline Missing & $0(0.0 \%)$ & $0(0.0 \%)$ & $3(3.8 \%)$ & $1(0.5 \%)$ & $4(1.0 \%)$ & \\
\hline PR status & & & & & & 0.28 \\
\hline Negative & 31 (33.0\%) & 24 (48.0\%) & $25(31.6 \%)$ & 73 (37.1\%) & $153(36.4 \%)$ & \\
\hline Positive & $63(67.0 \%)$ & $26(52.0 \%)$ & $51(64.6 \%)$ & $123(62.4 \%)$ & $263(62.6 \%)$ & \\
\hline Missing & $0(0.0 \%)$ & $0(0.0 \%)$ & $3(3.8 \%)$ & $1(0.5 \%)$ & $4(1.0 \%)$ & \\
\hline
\end{tabular}


Table 2 Post-operation follow-up during the first 3 years by sociodemographic and clinical profile $(N=420)$ (Continued)

\begin{tabular}{|c|c|c|c|c|c|c|}
\hline \multirow[t]{2}{*}{ Characteristic } & \multicolumn{4}{|c|}{ Frequency of follow-up in the first 3 years } & \multirow{2}{*}{$\begin{array}{l}\text { Total } \\
N=420\end{array}$} & \multirow[t]{2}{*}{$p^{*}$} \\
\hline & $0 n=94$ & $1 n=50$ & $2 n=79$ & $3 n=197$ & & \\
\hline HER2 status & & & & & & 0.41 \\
\hline Negative & 77 (81.9\%) & $38(76.0 \%)$ & $65(82.3 \%)$ & $152(77.2 \%)$ & $332(79.0 \%)$ & \\
\hline Positive & $17(18.1 \%)$ & $12(24.0 \%)$ & $11(13.9 \%)$ & $44(22.3 \%)$ & $84(20.0 \%)$ & \\
\hline Missing & $0(0.0 \%)$ & $0(0.0 \%)$ & $3(3.8 \%)$ & $1(0.5 \%)$ & $4(1.0 \%)$ & \\
\hline Breast surgery & & & & & & 0.24 \\
\hline Lumpectomy & $38(40.4 \%)$ & $20(40.0 \%)$ & $35(44.3 \%)$ & $101(51.3 \%)$ & $194(46.2 \%)$ & \\
\hline Mastectomy & $56(59.6 \%)$ & $29(58.0 \%)$ & $44(55.7 \%)$ & $95(48.2 \%)$ & $224(53.3 \%)$ & \\
\hline Missing & $0(0.0 \%)$ & $1(2.0 \%)$ & $0(0.0 \%)$ & $1(0.5 \%)$ & $2(0.5 \%)$ & \\
\hline Axillary surgery & & & & & & 0.03 \\
\hline Sentinel lymph node biopsy & $37(39.4 \%)$ & $24(48.0 \%)$ & $40(50.6 \%)$ & $108(54.8 \%)$ & $209(49.8 \%)$ & \\
\hline Axillary lymph node dissection & $50(53.2 \%)$ & $24(48.0 \%)$ & $36(45.6 \%)$ & $88(44.7 \%)$ & $198(47.1 \%)$ & \\
\hline Missing & $7(7.4 \%)$ & $2(4.0 \%)$ & $3(3.8 \%)$ & $1(0.5 \%)$ & $13(3.1 \%)$ & \\
\hline Chemotherapy & & & & & & $<0.01$ \\
\hline No & $47(50.0 \%)$ & $12(24.0 \%)$ & $12(15.2 \%)$ & $28(14.2 \%)$ & $99(23.6 \%)$ & \\
\hline Yes & $47(50.0 \%)$ & $38(76.0 \%)$ & $67(84.8 \%)$ & 169 (85.8\%) & $321(76.4 \%)$ & \\
\hline Radiotherapy & & & & & & $<0.01$ \\
\hline No & $62(66.0 \%)$ & $23(46.0 \%)$ & $25(31.6 \%)$ & $39(19.8 \%)$ & $149(35.5 \%)$ & \\
\hline Yes & $32(34.0 \%)$ & $27(54.0 \%)$ & $54(68.4 \%)$ & $158(80.2 \%)$ & $271(64.5 \%)$ & \\
\hline Targeted therapy & & & & & & 0.03 \\
\hline No & $90(95.7 \%)$ & $45(90.0 \%)$ & $73(92.4 \%)$ & $167(84.8 \%)$ & $375(89.3 \%)$ & \\
\hline Yes & $4(4.3 \%)$ & $5(10.0 \%)$ & $6(7.6 \%)$ & $30(15.2 \%)$ & $45(10.7 \%)$ & \\
\hline Endocrine therapy & & & & & & $<0.01$ \\
\hline No & $40(42.6 \%)$ & $24(48.0 \%)$ & $17(21.5 \%)$ & $60(30.5 \%)$ & $141(33.6 \%)$ & \\
\hline Yes & 54 (57.4\%) & $26(52.0 \%)$ & 62 (78.5\%) & 137 (69.5\%) & 279 (66.4\%) & \\
\hline
\end{tabular}

Abbreviations: ER Estrogen receptor status, PR Progesterone receptor status, HER 2 Human epidermal growth factor receptor 2

${ }^{*} p$ from chi-square test or Fisher's exact test based on complete cases

at the provincial or city level has not been fully established or well functioned [17]. In addition, targeted procedures to promote post-surgery $\mathrm{FU}$ in subgroups was unable to be implemented due to missing evidence. This study provided some evidence to promote FU among subgroups. Further investigations on the feasibility of implementing routinely collected PROM (patient reported outcome indicators) and its impact on improving FU care of breast cancer patients in China is needed [18], as systematic review of 34 studies mostly among Caucasians reported PROM collection in routine breast cancer care is feasible and has promising results [19].

We found that elderly breast cancer patients were prone to loss of $\mathrm{FU}$, which was consistent with other studies $[14,16,20,21]$. Older patients are more likely diagnosed with other comorbidities such as hypertension and diabetes and frail to have a FU visit. In addition, elder patients have lower level of education as showed from the China's national data, which limit patients' understanding of the disease and its treatment regimens, and the importance of post-surgery FU [22]. On the other hand, it has been confirmed that patients can benefit from education and counselling, which has positive impact on medication adherence [23].

We found among this group of patients in central China, poor FU adherence was significantly associated with lower insurance coverage, possibly due to financial stress. Cancer-related "financial toxicity" [24] is a major obstacle for patients to have FU examination or to continue treatment after surgery as indicated from our study in patients with breast cancer from the same hospital [25]. An American survey of patients with early-stage breast cancer reported that $77 \%$ of patients had financial burden related to the disease [26], similar to another American study indicating that $44 \%$ of breast cancer patients had at least moderate economic difficulties, and up to $88 \%$ were concerned about treatment-related costs [27]. Clinicians should take this into consideration and discuss with patients for informed decision to improve FU for better clinical outcome. In addition, policy support, 
Table 3 Factors associated with loss of follow-up in the first 3 years after surgery $(N=420)$

\begin{tabular}{|c|c|c|}
\hline Characteristic & $\begin{array}{l}\text { Unadjusted OR } \\
(95 \% \mathrm{Cl})\end{array}$ & $\begin{array}{l}\text { Adjusted OR } \\
(95 \% \mathrm{Cl}) *\end{array}$ \\
\hline \multicolumn{3}{|l|}{ Age(years) } \\
\hline$\leq 65$ & 1.0 & 1.0 \\
\hline$>65$ & $5.70(3.28-9.92)$ & $2.31(1.13-4.73)$ \\
\hline \multicolumn{3}{|c|}{ Medical insurance coverage } \\
\hline High ( $\geq 70 \%)$ & 1.0 & 1.0 \\
\hline Medium (50-70\%) & $2.36(1.28-4.36)$ & $3.21(1.53-6.73)$ \\
\hline Low $(<50 \%)$ & $2.86(1.44-5.66)$ & $3.58(1.57-8.15)$ \\
\hline
\end{tabular}

Family history

Negative 1.0

Positive

1.0

Marital status

Married

Unmarried

$2.20(0.93-5.19)$

\section{Employment status}

Employed

1.0

Unemployed

$1.15(0.58-2.28)$

Retired

$0.77(0.42-1.41)$

Tumor size (cm)

$\begin{array}{ll}0-1.9 & 1.0 \\ 2-4.9 & 1.28(0.79-2.09) \\ >5 & 2.44(0.89-6.68)\end{array}$

Positive axillary nodal status

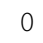

$1-3$

$4-9$

$\geq 10$

TNM stage

Stage 0-I

Stage II

Stage III

Histological subtype

In Situ
Ductal/Lobular/Mixed/Metaplastic
Tubular/Mucinous/Papillary

ER

$\begin{array}{ll}\text { Negative } & 1.0 \\ \text { Positive } & 1.32(0.79-2.20)\end{array}$

PR

$$
\text { Negative }
$$

1.0

Positive

$1.24(0.76-2.01)$

HER2

$\begin{array}{ll}\text { Negative } & 1.0 \\ \text { Positive } & 0.84(0.47-1.52)\end{array}$

Table 3 Factors associated with loss of follow-up in the first 3 years after surgery $(N=420)$ (Continued)

\begin{tabular}{|c|c|c|}
\hline Characteristic & $\begin{array}{l}\text { Unadjusted OR } \\
(95 \% \mathrm{Cl})\end{array}$ & $\begin{array}{l}\text { Adjusted OR } \\
(95 \% \mathrm{Cl})^{*}\end{array}$ \\
\hline \multicolumn{3}{|l|}{ Surgery of breast } \\
\hline Lumpectomy & 1.0 & \\
\hline Mastectomy & $1.37(0.86-2.18)$ & \\
\hline \multicolumn{3}{|l|}{ Axillary surgery } \\
\hline Sentinel lymph node biopsy & 1.0 & 1.0 \\
\hline Axillary lymph node dissection & $1.57(0.97-2.53)$ & $2.51(1.39-4.52)$ \\
\hline \multicolumn{3}{|l|}{ Chemotherapy } \\
\hline Yes & 1.0 & 1.0 \\
\hline No & $5.27(3.19-8.70)$ & $3.48(1.84-6.57)$ \\
\hline \multicolumn{3}{|l|}{ Radiotherapy } \\
\hline Yes & 1.0 & 1.0 \\
\hline No & $5.32(3.25-8.71)$ & $3.90(2.14-7.10)$ \\
\hline \multicolumn{3}{|l|}{ Targeted therapy } \\
\hline Yes & 1.0 & \\
\hline No & $3.24(1.13-9.28)$ & \\
\hline \multicolumn{3}{|l|}{ Endocrine therapy } \\
\hline Yes & 1.0 & \\
\hline No & $1.65(1.03-2.64)$ & \\
\hline
\end{tabular}

Abbreviations: $E R$ Estrogen receptor status, $P R$ Progesterone receptor status, HER 2 Human epidermal growth factor receptor 2

*Adjusted ORs in the final model from step-wise logistic regression analysis by including all the variables in the Table with $P<0.10$ from univariate logistic regression and eliminate each at a time justified by likelihood ratio test [13]

especially for patients with high recurrence risk, should be developed by incorporating necessary FU examinations into the medical insurance system.

This study shows that extensive axillary surgery was associated with the increased risk of loss of FU. Theoretically speaking, patients with the extensive surgery are more prone to lymphedema requiring close FU. Rather, the previous researches have consistently found that patients with more serious disease are more likely to give up disease management $[28,29]$. These results indicated the needs for clinicians to attempt psychological consultation or education during the FU for patients to foster a positive attitude of their current physical condition and to alleviate or eliminate the negative emotions including fear and anxiety [30]. It could facilitate patients' understanding of the condition and the treatment and active participation in decision-making.

We found that patients having had radiotherapy or chemotherapy were more likely to FU examinations after surgery. This result was consistent with the reports by Enright and Neuman that breast cancer patients who have undergone more intensive treatment have better adherence and more frequent FU [20, 31]. Generally speaking, patients with more severe disease should be 
treated with more intensive treatment. This suggests that the association with FU adherence of intensive treatment cannot be explained by severity of disease alone but related to treatment adherence. For example, it is reported that adherence with endocrine therapy fell from $90 \%$ in the first year to $50 \%$ at the fifth year [32]. The same decreased trend was also observed in our patients. Further study is needed to prove the relationship between the follow-up and treatment adherence.

Limitations of the study should be noted. Firstly, the loss of FU rate may be overestimated considering that some patients may go to other local hospitals for the post-surgery FU due to various reasons such as transportation. Secondly, the loss of FU in the first 3 years was investigated and the evaluation of long-term FU assessment was not available due to the limited case numbers. Lastly, the impact of adherence to FU examination on survival warrants further assessment.

Despite those limitations, we were able to identify subgroup among this cohort of breast patients with higher probability of loss post-operation FU. This could help health care staff to make more efforts to track the subgroups and to apply more rigorous post-surgery patient care. In addition, there is a need at the government level to establish a high-level database to comprehensively and accurately track the care and the survival of patients after surgery.

\section{Conclusions}

To sum up, we found that the annual FU rate after curative surgery for breast cancer survivors decreased significantly within 5 years, and that the probability of poor adherence to FU examinations was significantly higher in patients aged over 65 years with lower medical insurance coverage, having extensive axillary lymph node dissection, and no radiotherapy or chemotherapy. These results suggested the need for improving adherence to FU in higherrisk subgroups and help clinicians to develop tailored patient management after curative surgery.

\section{Supplementary Information}

The online version contains supplementary material available at https://doi. org/10.1186/s12885-020-07600-y.

Additional file 1: Table S1. Annual follow-up among 711 patients during 2012-2019. Table S2. Factors associated with loss of follow-up at the 3rd year after surgery $(N=420)$. Figure $\mathbf{S 1}$. Patients included in the analyses during 2012-2018.

\section{Abbreviations}

NCCN: National Comprehensive Cancer Network; ER: Estrogen receptor; PR: Progesterone receptor; HER 2: Human epidermal growth factor receptor 2; OR: Odds ratio; 95\% Cl: 95\% confidence interval

\section{Acknowledgements}

The authors would like to thank Ms. Li Hao for giving technical support in statistical analyses.

\section{Authors' contributions}

All authors contributed to the study conception and design. FR extracted and analyzed the data and prepared the first draft; JJF interpreted the data; ZXJ prepared the tables; LM contributed to the critical review of the manuscript; GJN supervised and contributed to the critical review of the manuscript. All authors read and approved the final manuscript.

\section{Funding}

The data collection and analysis were supported by "136 project award" from Shanxi provincial government.

\section{Availability of data and materials}

All data generated or analyzed during this study are included in this published article and its supplementary information files. The original data are available upon request to the corresponding author.

\section{Ethics approval and consent to participate}

The research has been approved by Ethics Committee of Shanxi Bethune Hospital (No: YXLL-2019-130). Individual consent to participate was waived due to the nature of administrative registry data and participant privacy is protected through the use of non-identifiable data and by only reporting aggregated data.

\section{Consent for publication}

Not applicable.

\section{Competing interests}

The authors declare that they have no competing interests.

\section{Author details}

'Department of Breast Surgery, The Affiliated Shanxi Bethune Hospital of Shanxi Medical University, 99 Longcheng Street, Taiyuan 030032, Xiaodian District, China. ${ }^{2}$ Cancer Research Institute, University of South Australia, Adelaide 5000, Australia.

Received: 3 March 2020 Accepted: 30 October 2020

Published online: 12 November 2020

\section{References}

1. Zhang ML, Peng P, Wu CX, Gong YM, Zhang SW, Chen WQ, et al. Report of breast cancer incidence and mortality in China registry regions,2008-2012. Zhonghua Zhong Liu Za Zhi. 2019;41:315-20.

2. Bray F, Ferlay J, Soerjomataram I, Siegel RL, Torre LA, Jemal A. Global cancer statistics 2018: GLOBOCAN estimates of incidence and mortality worldwide for 36 cancers in 185 countries. CA Cancer J Clin. 2018;68:394-424.

3. Chen W, Zheng R, Baade PD, Zhang S, Zeng H, Bray F, et al. Cancer statistics in China, 2015. CA Cancer J Clin. 2016;66:115-32.

4. Waks AG, Winer EP. Breast cancer treatment: a review. JAMA. 2019;321: 288-300.

5. Clinical Practice Guidelines in Oncology. Breast cancer - V.3: National Comprehensive Cancer Network; 2019. https://www.nccn.org/professionals/ development.aspx. Accessed 25 Nov 2019.

6. Ma F, Xu BH, Shao ZM, et al. Comprehensive management guideline for breast cancer follow-up and concomitant diseases. Zhonghua Zhong Liu Za Zhi. 2019;41:29-41.

7. Colleoni M, Sun Z, Price KN, Karlsson P, Forbes JF, Thürlimann B, et al. Annual Hazard rates of recurrence for breast cancer during 24 years of follow-up: results from the international breast cancer study group trials I to V. J Clin Oncol. 2016;34:927-35.

8. Liu J, Jiang Y, Qian M, LV L, Ying X. The improved effects of a multidisciplinary team on the survival of breast cancer patients: experiences from China. Int J Environ Res Public Health. 2019;17:277.

9. Sumit KS, Mayumi N, Benjamin JL. Examining aspects of successful community-based programs promoting cancer screening uptake to reduce cancer health disparity: a systematic review. Prev Med. 2020. https://doi.org/ 10.1016/j.ypmed.2020.106242.

10. Emma R, Amanda EH, Anna C, Katy S, Alison R, Vibe HP. Telephone interventions for symptom management in adults with cancer. Cochrane Database Syst Rev. 2020. https://doi.org/10.1002/14651858.CD007568.pub2. 
11. Natoli C, Brocco D, Sperduti I, Nuzzo A, Tinari N, Tursi MD, et al. Breast cancer "tailored follow-up" in Italian oncology units: a web-based survey. PLoS One. 2014. https://doi.org/10.1371/journal.pone.0094063.

12. Gill A, Gosain R, Bhandari S, Gosain R, Gill G, Abraham J, et al. "Lost to follow-up" among adult cancer survivors. Am J Clin Oncol. 2018;41:1024-7.

13. Hosmer D, Lemeshow S. In: Hosmer D, Lemeshow S, editors. Modelbuilding strategies and methods for logistic regression. New York City: Wiley; 1989. p. 82-126.

14. Lu W, Jansen L, Schaapveld M, Baas PC, Wiggers T, Bock GHD. Underuse of long-term routine hospital follow-up care in patients with a history of breast cancer? BMC Cancer. 2011. https://doi.org/10.1186/1471-2407-11-279.

15. Grunfeld E, Hodgson DC, Giudice ME, Moineddin R. Population-based longitudinal study of follow-up Care for Breast Cancer Survivors. J Oncol Pract. 2010;6:174-81.

16. Schapira MM, MCAuliffe TL, Nattinger AB. Underutilization of mammography in older breast cancer survivors. Med Care. 2010;38:281-9.

17. Mary LM, Patti AG, Kathleen D, Cynthia K, Li J, Marlo W, et al. Adherence to quality breast cancer survivorship care in four Canadian provinces: a CanIMPACT retrospective cohort study. BMC Cancer. 2019;19:659-70

18. Richard GM. How to include patient-reported outcome measures in clinical trials. Curr Osteoporos Rep. 2020. https://doi.org/10.1007/s11914-020-00611-5.

19. Laurentine SEE, Arvind O, Lisanne MV, Hester FL, Linetta BK, Cornelis V, et al. Implementing patient-reported outcome measures in clinical breast cancer care: a systematic review. Value Health. 2019;22:1197-226.

20. Neuman HB, Weiss JM, Schrag D, Ronk K, Havlena J, LoConte NK, et al. Patient demographic and tumor characteristics influencing oncologist follow-up frequency in older breast cancer survivors. Ann Surg Oncol. 2013; 20:4128-36.

21. Onega T, Weiss J, Diflorio R, Mackenzie T, Goodrich M, Poplack S. Evaluating surveillance breast imaging and biopsy in older breast cancer survivors. Int J Breast Cancer. 2012. https://doi.org/10.1155/2012/347646.

22. Wang $X, X u B$, Liang $H$, Jiang $S$, Tan $H$, Wang $X$, et al. Distribution characteristics and factors influencing oral warfarin adherence in patients after heart valve replacement. Patient Prefer Adherence. 2018;12:1641-8.

23. Wilhelmsen NC, Eriksson T. Medication adherence interventions and outcomes: an overview of systematic reviews. Eur J Hosp Pharm. 2019; 26:187-92.

24. Zafar SY, Abernethy AP. Financial toxicity, part I: a new name for a growing problem. Oncology (Williston Park). 2013;27:80-1,149

25. Jing JF, Feng R, Zhang XJ, Li M, Gao J. Financial toxicity and its associated patient and cancer factors among women with breast cancer: a singlecenter analysis of low-middle income region in China. Breast Cancer Res Treat. 2020;181:435-43.

26. Jagsi R, Pottow JA, Griffith KA, Bradley C, Hamilton AS, Graff J, et al. Longterm financial burden of breast cancer: experiences of a diverse cohort of survivors identified through population-based registries. J Clin Oncol. 2014; 32:1269-76

27. Irwin B, Kimmick G, Altomare I, Marcom PK, Houck K, Zafar SY, et al. Patient experience and attitudes toward addressing the cost of breast cancer care. Oncologist. 2014;19:1135-40

28. Jackson LA, Nelson JC, Benson P, Neuzil KM, Reid RJ, Psaty BM, et al. Functional status is a confounder of the association of influenza vaccine and risk of all-cause mortality in seniors. Int J Epidemiol. 2006;35:345-52.

29. Keating NL, Landrum MB, Guadagnoli E, Winer EP, Ayanian JZ. Factors related to underuse of surveillance mammography among breast cancer survivors. J Clin Oncol. 2006;24:85-94.

30. Berendsen AJ, Roorda C, Jansen L, de Bock GH. Patients' beliefs about the aims of breast cancer follow-up: a qualitative study. Maturitas. 2016;91:140-4.

31. Enright K, Desai T, Sutradhar R, Gonzalez A, Powis M, Taback N, et al. Factors associated with imaging in patients with early breast cancer after initial treatment. Curr Oncol. 2018:25:126-32.

32. Robinson B, Dijkstra B, Davey V, Tomlinson S, Frampton C. Adherence to adjuvant endocrine therapy in Christchurch women with early breast cancer. Clin Oncol (R Coll Radiol). 2018. https:/doi.org/10.1016/j.clon.2017.10.015.

\section{Publisher's Note}

Springer Nature remains neutral with regard to jurisdictional claims in published maps and institutional affiliations.

Ready to submit your research? Choose BMC and benefit from:

- fast, convenient online submission

- thorough peer review by experienced researchers in your field

- rapid publication on acceptance

- support for research data, including large and complex data types

- gold Open Access which fosters wider collaboration and increased citations

- maximum visibility for your research: over $100 \mathrm{M}$ website views per year

At BMC, research is always in progress.

Learn more biomedcentral.com/submissions 